\title{
Searching for a Silver Lining: Mediated Intergroup Contact and Mental Health Perceptions
}

\author{
Kathryn L. Lookadoo ${ }^{1}$, Norman C. H. Wong ${ }^{2}$ \\ ${ }^{1}$ Naveen Jindal School of Management, University of Texas at Dallas, Dallas, Texas, USA \\ ${ }^{2}$ Department of Communication, University of Oklahoma, Norman, Oklahoma, USA \\ Correspondence: Norman C. H. Wong, Department of Communication, University of Oklahoma, Norman, Oklahoma, \\ USA.
}

Received: May 4, 2020

doi:10.11114/smc.v8i2.4834
Accepted: June 4, 2020

Online Published: June 19, 2020

URL: https://doi.org/10.11114/smc.v8i2.4834

\begin{abstract}
This study investigated viewer responses to characters from Silver Linings Playbook, a movie about characters dealing with mental illness, from the perspective of mediated intergroup contact hypothesis. Researchers tested if identification with fictional characters with mental illness reduced viewers' negative stereotypes about mental illness and increased their willingness to support people with the same illnesses as the characters. Additionally, empathy was tested as a mediator between identification and stereotype reduction. One hundred forty-five participants were randomly assigned to 1 of 3 character conditions. The hypotheses associated with identification and stereotypes and intentions were partially supported. For two characters, empathy mediated the relationship between identification and negative stereotypes. Implications for mediated portrayals of health issues and behaviors are discussed.
\end{abstract}

Keywords: Mediated intergroup contact; stereotypes; identification; mental illness; perception

\section{Introduction}

Consistently, media depictions of people with mental illness are sensationalized, inaccurate, and negative (Wahl, 1992; Stout, Villegas, \& Jennings, 2004; Klin \& Lemish, 2008). Media depicts people with mental illness as violent, erratic, and dangerous (Benbow, 2006; Diefenbach, 1997; Parrott \& Parrott, 2015). Stout et al. (2004) found that media's representation of mental illness played a role in shaping or influencing audiences' attitudes and knowledge about and furthering prejudice toward mental illness. The mass media, in its various forms (television, broadcast news, movies, etc.) serve as a primary source of information about mental illness for many Americans (Yakelovich, 1990). Although a fair amount of research has highlighted different ways media have perpetuated mental illness stigma via negative portrayals of characters with mental illness, communication of misinformation about mental illness, and reinforcement of negative stereotypes about mental illness (e.g., Wahl, 1992), little is known about how the mass media may help reduce mental illness stigma. Allport's (1954) contact theory provides a useful framework to help address this research gap.

In the late 1990s, researchers began to consider how Allport's (1954) contact theory could function in a mediated setting. For instance, Tan, Fujioka, and Lucht (1997) and Fujioka (1999) studied how "vicarious contact" with out-group representatives through media impacts impressions of African Americans and Native Americans, respectively. Researchers continue to test whether exposure to characters from minority populations can reduce prejudice toward those populations. Although preliminary results are promising (e.g. Hoffner \& Cohen, 2012; Ortiz \& Harwood, 2007; Schiappa, Gregg, \& Hewes, 2005; Schiappa, Gregg, \& Hewes, 2006), more research should be done to examine the extent media portrayals of stigmatized groups (e.g., individuals with mental illness issues) can help to address stereotypes about those groups.

The present study examines mediated intergroup contact in the context of mental illness through an experiment using the film Silver Linings Playbook. The goal is to determine whether exposure to different characters featured in the film and the strength of identification with those characters leads to reduced negative stereotypes and increased willingness to support people with the same mental disorders as the ones portrayed in the movie (i.e., bipolar disorder, obsessive-compulsive disorder, and major depression). Also, this study tests if empathy mediates the relationships between identification and stereotypes and willingness to support people with mental illness. 


\section{Literature Review}

Mental illnesses are common ailments worldwide. For instance, the World Health Organization (WHO; 2019) reports that depression affects an estimated 264 million people and bipolar affective disorder impacts 45 million people. Additionally, over 250 million suffer from a variety of anxiety disorders (WHO, 2017). Despite the pervasiveness of mental illness, the general public tends to hold negative attitudes and beliefs about people with mental illness which can lead to social exclusion, exploitation, and discrimination (Stuart, 2016). These prejudices toward people with mental illness lead to those with mental illnesses to feel a stigma related to their condition which can lead to a fear of disclosure of mental illness issues and deterrence from seeking treatment (Centers for Disease Control and Prevention et al., 2010).

\subsection{Mental Illness Portrayals in the Media}

While not the sole contributor to mental illness stigma, media play an important role in stigmatizing mental illness (Ma, 2017). Stout et al. (2004) argue that media outlets serve as many people's main information source about mental illness. Multiple literature reviews (Wahl, 1992; Stout et al., 2004; Ma, 2017) that span decades of media's depiction of mental illness found that media portrays mental illness were inaccurate and negative. More specifically, television and film tend to misrepresent mental illness most often, compared to print media (Stout et al., 2004), with both news and fictional media perpetuating a negative image of mental illness (Ma, 2017). For instance, in crime dramas, individuals with mental illness were more likely to commit a crime or be violent than other characters (Parrott \& Parrott, 2015). Additionally, people diagnosed with mental illness were depicted as unlikable and dangerous. Further, media depictions misrepresent the causes and treatments of mental illness and distort mental health professionals as well (Klin \& Lemish, 2008). While children's television rarely shows characters with a mental illness, when they do, the programs portray characters as aggressive and threatening. Also, in children's programming, characters without a mental illness typically fear, exclude, and disrespect characters with a mental illness (Wahl, Hanrahan, Karl, Lasher, \& Swaye, 2007). However not all depictions are negative; portrayals of people with obsessive-compulsive disorder (OCD) in fictional media often are positive with characters appearing intelligent (Fennell \& Boyd, 2014; Siegel, 2014).

These negative images of mental illness have significant implications for public prejudice and stigma toward people with mental illness. Media effects research documents how influential the media can be in shaping public perceptions (e.g., cultivation, media priming theory). For instance, Granello and Pauley (2000) found that negative media depictions of mental illness can be highly influential for people without direct knowledge or experience with mental illness, who use media as their primary source for mental illness information. Additionally, high consumers of media portrayals of people with mental illness tend to express more prejudice and stigma (Klin \& Lemish, 2008) and intolerance (Granello \& Pauley, 2000). However, fictional media has the potential to have a positive impact on mental illness attitudes through more positive portrayals of mental illness and the opportunity for users to connect with characters with mental illness.

\subsection{Contact Hypothesis}

Allport's (1954) intergroup contact hypothesis describes prejudice as an outcome of a rushed generalization about another group founded on deficient or incorrect information. He explained that prejudice against and negative affect toward an out-group can be reduced if the prejudiced, in-group individual maintains sustained personal contact with an out-group member and learns more information about that group. This positive contact results in attitude change by which a person modifies their attributes of that group in memory (Rothbart \& John, 1985). Pettigrew \& Tropp's (2006) meta-analysis of 515 contact studies found a moderate negative correlation between contact and prejudice, thus supporting the contact hypothesis.

Contact alone does not always result in attitude change. Allport (1954) argued sustained and nonsuperficial contact is important to create dissonance between the in-group member's negative out-group beliefs and their new perceptions of the out-group, which results in attitude change (Schiappa et al., 2005). Additionally, this contact must be positive and generalizable. Desforges, Lord, and Pugh (2007) explained, if an in-group member believes that the out-group member does not represent all members of that out-group, they will not modify attitudes toward the out-group. Building on contact theory, "extended contact hypothesis" research demonstrated that cross-group friendship can be an important factor in prejudice reduction (Amir, 1976; Page-Gould, Mendoza-Denton, \& Tropp, 2008). For instance, "knowledge that an in-group member has a close relationship with an out-group member can lead to more positive intergroup attitude" (Wright, Aron, McLaughlin-Volpe, \& Ropp, 1997, p. 74).

\subsection{Mediated Intergroup Contact}

Although positive intergroup contact can reduce prejudice and stereotyping, generally, people do not have sustained, positive contact with out-groups. Media portrayals of out-groups can offer viewers an opportunity to vicariously interact with out-group representatives (Eyal \& Dailey, 2012; Kanazawa, 2002). Using contact theory as a foundation, 
researchers have examined how specific engagement variables (e.g., parasocial interaction, identification, empathy) may facilitate mediated prejudice reduction.

For instance, Schiappa et al. (2005) tested whether the contact hypothesis would work in a mediated setting through parasocial phenomena. Horton and Wohl (1956) described parasocial interaction (PSI) as a pseudo face-to-face relationship between a media user and media figure. PSI pertains to how media users interact with media personalities, "persona," as if they are participating in an interpersonal conversation (Auter \& Palmgreen, 2000). As a parasocial relationship (PSR) grows, an audience member feels as if they understand the persona and form a bond that exists outside a media-viewing situation (Cortese \& Rubin, 2010).

Schiappa et al. (2005) found support for the parasocial contact hypothesis (PCH) in three studies that parasocial contact with gay men and transvestites was associated with lower prejudice levels. Consistent with the $\mathrm{PCH}$, a study on the television series, Monk, found people reporting stronger PSRs with the titular character had lower negative stereotypes toward and less desired social distance from people with OCD, than those with weaker PSRs (Hoffner \& Cohen, 2012). In addition to parasocial phenomena, scholars advise that media user-figure interactions like identification should be tested in terms of the ability to reduce prejudice (Ortiz \& Harwood, 2007). Scholars have defined and operationalized identification in disparate ways (Murphy, Frank, Chatterjee, \& Baezconde-Garbanati, 2013). For this present study, identification is when a media user temporarily merges their identity with a fictional character (Cohen, 2006). Ortiz and Harwood (2007) considered identification in their "mediated intergroup contact hypothesis" (MICH) which is similar to $\mathrm{PCH}$. They suggested that contact could be achieved by a media user identifying with an in-group character who interacted with an out-group character. Through identification with in-group characters who had positive interactions with out-group characters, viewers could learn positive attitudes toward out-group members through abstract modeling. Their MICH study's results were promising but mixed, showing that additional research is needed. Joyce and Harwood (2012) also found evidence suggesting that identification with in-group characters who have positive interactions with out-group characters can lead to more positive out-group perceptions.

Both the $\mathrm{PCH}$ and $\mathrm{MICH}$ involve positive interactions with an out-group member whether it is through parasocial contact with an out-group member or identification with an in-group member who has an interaction with an out-group member. Building on this research, Park (2012) suggested the possibility of reducing prejudice if an audience member had a PSI with an in-group character, who had an interaction with an out-group character (i.e., a friend of a friend interaction). However, could identification with an out-group character reduce prejudice toward out-groups? Unlike traditional interpersonal contact, mediated contact allows media consumers to adopt out-group members' perspectives through identification. In this emotional and cognitive identification process, the viewer experiences the narrative from the character's perspective and forgets their identity as an audience member (Cohen, 2001). Conversely, when individuals hold PSIs and PSRs, they maintain their identity and remain separate from the character because they see the character as a friend, rather than seeing themselves as the character (Cohen, 2009). In addition to the empathic component, identification involves three other dimensions: cognitive (sharing the character's perspective), motivational (internalization of character's goals), and absorption in the narrative (Cohen, 2009; Moyer-Gusé, 2008). The final dimension, absorption, is similar to the concept of transportation, which occurs when a person becomes swept up into a narrative and loses a sense of his or her surroundings or reality (Potter \& Zillmann, 2009). However, identification focuses on the absorption with one character rather than the overall storyline (Moyer-Gusé, 2008). Identification with characters is positively associated with changes in cognition, attitudes, behavioral intentions, and behavior (Murphy et al., 2013).

McLaughlin and Rodriguez (2017) found that identification mediated the relationship between exposure to gay television characters and acceptance of gay people. Thus, lending positive support to the idea that direct identification with the out-group character can facilitate stereotype reduction. This present study builds on this mediated contact through identification research by testing how identification with an out-group character impacts levels of negative stereotypes toward people with mental illness.

H1: Level of identification with a character with mental illness will be negatively associated with stereotypes regarding the character's condition.

H2: Level of identification with a character with mental illness will be positively associated with willingness to support others with the character's condition.

\subsection{Mediated Intergroup Contact and Empathy}

Scholars suggest that mediated contact with out-group members helps reduce prejudice toward out-groups by eliciting empathic concern for stigmatized individuals. Researchers have shown empathy to be a factor in reducing stigmatization (Batson et al., 1997; Oliver, Dillard, Bae, \& Tamul, 2012). For example, Batson et al. (1997) found that when participants were encouraged to engage in greater perspective-taking with a stigmatized out-group member (e.g., 
a person with AIDS or a homeless person), negative stereotypes toward these groups were reduced and more positive attitudes were reported. Similarly, Oliver et al. (2012) found when individuals were exposed to narrative news stories about a stigmatized group (e.g., prisoners, immigrants), their attitudes toward the overall group became more positive only when they felt a high degree of compassion towards the stigmatized individuals. Compassion helped mediate the relationship between mediated contact and attitudes toward out-groups.

Relating these findings to the present study, the authors expect identification towards a character with a mental illness be positively assoeciated with empathy towards the character. This in turn should be negatively related to stereotypes toward the character's condition, and positively related to willingness to help others with the same condition. Identification is a related but distinct concept from empathy. In this study, character identification is defined as an audience member imagining himself or herself being that character, assimilating his or her thoughts and feelings with the media character (Cohen, 2001). Empathy is defined more along the lines of perspective-taking (i.e., seeing things from the other person's point of view) and affective sharing, that is, experiencing the same emotions as the other person (Shen, 2010).

H3: Empathy felt toward a character with mental illness will mediate the relationship between identification with the character and negative stereotypes for the character's condition.

\section{Method}

\subsection{Participants, Procedure, and Stimuli}

A hundred forty-five undergraduate students (70.5\% female) at a large Midwestern university between the ages of 18 and 33 years $(M=20.9, S D=2.12)$ completed an IRB-approved, online, pretest-posttest experiment. After completing the consent form, participants answered a 10-15 minute pretest that asked them about PSRs and familiarity with actors in the four conditions, contact and experience with mental illness, mental illness stereotypes, willingness to support people with mental illness, media use, and demographics.

After a week, researchers notified participants that the posttest survey was available. Posttest participants were randomly assigned to 1 of 3, 13-minute video conditions. Each condition used several clips from Silver Linings Playbook (Russell, 2012) to depict a character's struggle with mental illness (e.g. Pat (Bradley Cooper): bipolar disorder; Pat Sr. (Robert DeNiro): OCD; and Tiffany (Jennifer Lawrence): major depression). Each video provided a synopsis of a character's storyline using only clips from the movie. The purpose of isolating a character's story was to get participants to focus on a specific character's mental illness. By measuring the mental illness conditions separately, the researchers could increase their confidence in whether the effect of identification or state empathy helps reduce the stigma toward that mental illness holds true for more than one type of mental illness (i.e., if the effect is found whether the mental illness condition examined is bipolar disorder or depression).

After watching their assigned video, participants completed measures of identification and state empathy with the character in their condition. Participants answered questions measuring negative stereotypes and willingness to support people with mental illness, familiarity with movie, and demographics.

\subsection{Measures}

\subsubsection{Contact with Mental Illness}

Hoffner and Cohen's (2012) measure assessed the amount of contact participants had with individuals with mental illness. Respondents answered how often $(1$, never; 4 , often $)$ they had contact with people with bipolar disorder $(M=$ $1.77, S D=2.54)$, major depression $(M=1.96, S D=2.03)$, and $\mathrm{OCD}(M=2.26, S D=2.29)$.

\subsubsection{Experience with Mental Illness}

Respondents reported whether they or a close family member or friend had any of the three mental illnesses (adapted from Hoffner \& Cohen, 2012). Participants who reported that they or a close family member had: Bipolar disorder (21.4\%), major depression (44.8\%), and OCD (23.4\%). Participants who reported having a close friend with Bipolar disorder (27.6\%), major depression (46.9\%), and OCD (20.1\%).

\subsubsection{Mental Illness Stereotypes}

Participants completed a 7-item scale for the three mental illnesses (Hoffner \& Cohen, 2012; van t'Veer, Kraan, Drosseart, \& Modde, 2006). They rated their agreement with the statements that people with each illness: are trustworthy, are able to maintain a regular job, tend to cause disturbances/inconveniences, are unable to take care of themselves, are intelligent, are dangerous, and will not recover (1, strongly disagree; 7 , strongly agree). Positive items were reverse coded. Pretest: Bipolar disorder: $M=4.06, S D=.76, \alpha=.73$; major depression: $M=3.70, S D=.82, \alpha$ $=.76$; OCD: $M=2.99, S D=.79, \alpha=.75$ ). Posttest: Bipolar disorder: $M=3.78, S D=.93, \alpha=.71$; major depression: $M$ $=3.58, S D=.92, \alpha=.71$; OCD: $M=3.10, S D=.80, \alpha=.75$ ). 


\subsubsection{Willingness to Support Causes for People with Mental Illness}

A modified version of Peng, Lee, and Heeter's (2010) measure assessed intention to support causes related to mental illness. Using a 7-point scale (1, not at all; 7, very much), participants rated their willingness to perform various actions (e.g., donate money, sign petition, discuss with others, pass on news articles) to assist people with mental illness. Pretest: Bipolar disorder: $M=3.94, S D=1.32, \alpha=.74$; major depression: $M=4.48, S D=1.40, \alpha=.79$; OCD: $M=3.73, S D=$ 1.34, $\alpha=.74)$. Posttest: Bipolar disorder: $M=3.83, S D=1.38, \alpha=.82$; major depression: $M=4.11, S D=1.50, \alpha=.83$; OCD: $M=3.74, S D=1.25, \alpha=.77)$.

\subsubsection{Parasocial Relationship}

This study measured PSR with actors (pretest) and characters (posttest) using the Parasocial-Interaction-Scale (Rubin \& Perse, 1987). Participants completed the 10-item, 7-point Likert scale (1, strongly disagree; 7, strongly agree). Respondents were asked to focus on a particular media-figure and express their agreement with statements like "[actor/character] makes me feel comfortable, like we are friends." The results were as follows: Bradley Cooper: $M=$ 5.11, $S D=.90, \alpha=.87$; Robert De Niro: $M=4.30, S D=.92, \alpha=.86$; Jennifer Lawrence: $M=5.63, S D=.97, \alpha=.89$; Pat: $M=4.12, S D=.96, \alpha=.86$; Pat Sr.: $M=3.83, S D=.73, \alpha=.71$; Tiffany: $M=4.09, S D=1.14, \alpha=.90$.

3.2.6 Familiarity with Actors

Participants indicated their familiarity with the three actors by answering the question "How familiar are you with [actor]?" on a 7-point scale (1, not at all familiar; 7, very familiar). Bradley Cooper: $M=5.35, S D=1.40$; Robert De Niro: $M=4.54, S D=1.70$; Jennifer Lawrence: $M=5.83, S D=1.26$.

\subsubsection{Identification}

To measure identification, participants completed the Tal-Or and Cohen (2010) 5-item, 7-point Likert scale (1, strongly disagree; 7, strongly agree). Respondents will be asked to focus on the character and answer statements like "While viewing, I felt like [character] felt." Pat: $M=4.25, S D=1.14, \alpha=.85$; Pat Sr.: $M=3.64, S D=1.02, \alpha=.80$; Tiffany: $M$ $=4.05, S D=1.22, \alpha=.87$.

\subsubsection{State Empathy}

Participants completed Shen's (2010) 12-item, 5-point state empathy scale for the character in their condition. Sample statements included, "I can relate to what [character] was going through" and "I can see [character]'s point of view" (1, not true at all; 5, completely true). Pat: $M=2.56, S D=.64, \alpha=.87$; Pat $\operatorname{Sr} .: M=2.29, S D=.57, \alpha=.84$; Tiffany: $M=$ 2.42, $S D=.74, \alpha=.92$.

\subsubsection{Familiarity with Silver Linings Playbook}

The researchers controlled for familiarity with the movie in two ways: (a) as a dichotomous variable $(0$, never seen the film; 1, seen the film) and (b) as an interval variable, the number of times people watched the film. Over half of the participants (58.6\%) had never seen the movie. Of those who have watched the movie, $66.7 \%$ had seen it only once, $21.7 \%$ of participants viewed the movie twice, and $11 \%$ saw it more than three times.

\section{Results}

\subsection{Test of Hypotheses}

We used multiple regression analyses for H1 and H2 and PROCESS Macro (Version 2.16; Hayes, 2016) for the H3 mediation model. In all analyses, the following variables were treated as covariates: Familiarity the movie, contact with someone with a mental illness (bipolar disorder, depression, and OCD); personal experience with mental illness; familiarity and PSR with the actors, and pretest measures of the dependent variables.

\subsubsection{Hypothesis One}

H1 predicted as identification with a character with mental illness increased, negative stereotypes regarding the character's condition would decrease. Covariates were controlled for and entered in the first block of the regression models. Stereotypes about bipolar disorder was regressed onto identification with Pat. Identification negatively predicted stereotypes about bipolar disorder, $\beta=-.44, t=-2.84, p<.05$, partial $r=-.43$, the overall model was significant, $F(8,35)=2.22, p<.05$, adjusted $R^{2}=.19$. Controlling for covariates, the more participants identified with Pat, the lower the negative stereotypes reported about bipolar disorder (see Table 1). 
Table 1. Regression of Negative Stereotypes about Bipolar Disorder on Identification with Pat (Bradley Cooper)

\begin{tabular}{lccccccc}
\hline Variable & \multicolumn{3}{c}{ Model 1 } & \multicolumn{3}{c}{ Model 2 } \\
& $B$ & $S E B$ & $B$ & $B$ & $S E B$ & $\beta$ \\
\hline Familiarity with the movie & .39 & .57 & .24 & .43 & .52 & .26 \\
\# of times watched the movie & .11 & .13 & .28 & .15 & .12 & .41 \\
Contact with person with bipolar disorder & -.17 & .09 & -.31 & -.11 & .08 & -.20 \\
Close friend with bipolar disorder & .50 & .46 & .18 & .49 & .42 & .17 \\
Personal experience with bipolar disorder & -.19 & .42 & -.07 & .09 & .39 & .04 \\
PSR with Bradley Cooper & -.08 & .21 & -.06 & .00 & .19 & .00 \\
Pretest neg. stereotypes about bipolar disorder & .35 & .21 & .30 & .18 & .20 & .16 \\
Identification with Pat & & & & -.47 & .17 & $-.44 * *$ \\
$R^{2}$ & & .18 & & & $.34 * *$ & \\
$F$ for change in $R^{2}$ & & 1.16 & & & $8.07 * *$ &
\end{tabular}

**indicates significance at $p<.01$

Identification with Pat Sr. did not predict stereotypes about $\mathrm{OCD}, \beta=-.22, t=-1.63, p=.11$, yet the overall model was significant, $F(8,40)=4.33, p<.001$, adjusted $R^{2}=.36$. The main predictor of stereotypes about OCD was participants' pretest stereotypes about OCD, $\beta=.59, t=4.44, p<.001$, partial $r=.57$. Participants' negative stereotypes about OCD were not greatly impacted by exposure to a character with the same condition (see Table 2).

Table 2. Regression of Negative Stereotypes about OCD on Identification with Pat Sr. (Robert De Niro)

\begin{tabular}{lcccccc}
\hline Variable & \multicolumn{3}{c}{ Model 1 } & \multicolumn{3}{c}{ Model 2 } \\
& $B$ & $S E B$ & $B$ & $B$ & $S E B$ & $\beta$ \\
\hline Familiarity with the movie & -.15 & .20 & -.16 & -.07 & .21 & -.07 \\
\# of times watched the movie & -.02 & .06 & -.10 & -.02 & .06 & -.07 \\
Contact with person with OCD & -.06 & .06 & -.15 & -.07 & .05 & -.19 \\
Close friend with OCD & -.10 & .27 & -.05 & .04 & .28 & .02 \\
Personal experience with OCD & .09 & .23 & .06 & .10 & .23 & .06 \\
PSR with Robert De Niro & -.12 & .14 & -.11 & -.09 & .14 & -.18 \\
Pretest neg. stereotypes about OCD & .63 & .14 & $.60 * *$ & .61 & .14 & $.59^{* *}$ \\
Identification with Pat Sr & & & & -.18 & .11 & -.22 \\
$R^{2}$ & & $.43^{* *}$ & & & .46 & \\
$F$ for change in $R^{2}$ & & $4.39^{* *}$ & & & & \\
\end{tabular}

**indicates significance at $p<.01$

Identification with Tiffany negatively predicted stereotypes about major depression,

$\beta=-.65, t=-5.28, p<.001$, partial $r=-.63$, and the overall model was significant, $F(8,43)=5.33, p<.001$, adjusted $R^{2}=.41$. Specifically, the more participants identified with Tiffany, the lower their negative stereotypes were about major depression (see Table 3). Taking the results overall, H1 was partially supported. 
Table 3. Regression of Negative Stereotypes about Depression on Identification with Tiffany (Jennifer Lawrence)

\begin{tabular}{lcccccc}
\hline Variable & \multicolumn{3}{c}{ Model 1 } & \multicolumn{3}{c}{ Model 2 } \\
& $B$ & $S E B$ & $B$ & $B$ & $S E B$ & $B$ \\
\hline Familiarity with the movie & -.03 & .28 & -.03 & .22 & .23 & .18 \\
\# of times watched the movie & .04 & .09 & .11 & .05 & .07 & .13 \\
Contact with person with depression & -.21 & .09 & $-.33^{*}$ & -.14 & .07 & $-.23^{*}$ \\
Close friend with depression & -.04 & .40 & -.02 & .14 & .32 & .06 \\
Personal experience with depression & -.32 & .38 & -.13 & -.22 & .30 & -.09 \\
PSR with Jennifer Lawrence & -.10 & .18 & -.08 & .08 & .14 & .07 \\
Pretest neg. stereotypes about depression & -.21 & .20 & -.17 & .02 & .17 & .02 \\
Identification with Tiffany & & & & -.66 & .12 & $-.65^{* *}$ \\
$R^{2}$ & & .17 & & & $.50^{* *}$ & \\
$F$ for change in $R^{2}$ & & 1.31 & & & $27.85^{* *}$ & \\
\hline
\end{tabular}

* indicates significance at $p<.05 ; * *$ indicates significance at $p<.01$

4.1.2 Hypothesis Two

$\mathrm{H} 2$ predicted as identification with a character with mental illness increased, willingness to support others with the same condition would also increase. Identification with Pat positively predicted willingness to help others with bipolar disorder, $\beta=.43, t=3.34, p<.01$, partial $r=.49$, and the overall model was significant, $F(8,35)=4.50, p<.01$, adjusted $R^{2}=.39$. The more people identified with Pat, the greater their willingness to support people with bipolar disorder, controlling for covariates (see Table 4).

Table 4. Regression of Willingness to Support People with Bipolar Disorder on Identification with Pat Jr. (Bradley Cooper)

\begin{tabular}{|c|c|c|c|c|c|c|}
\hline \multirow[b]{2}{*}{ Variable } & \multicolumn{3}{|c|}{ Model 1} & \multicolumn{3}{|c|}{ Model 2} \\
\hline & $B$ & $S E B$ & $B$ & $B$ & $S E B$ & $\beta$ \\
\hline Familiarity with the movie & -.41 & .60 & -.21 & -.56 & .53 & -.29 \\
\hline \# of times watched the movie & -.15 & .13 & -.33 & -.20 & .12 & -.44 \\
\hline Contact with person with bipolar disorder & .13 & .09 & .21 & .07 & .08 & .11 \\
\hline Close friend with bipolar disorder & .20 & .48 & .06 & .14 & .42 & .04 \\
\hline Personal experience with bipolar disorder & .09 & .44 & .03 & -.21 & .39 & -.07 \\
\hline PSR with Bradley Cooper & .37 & .22 & .23 & .29 & .20 & .18 \\
\hline $\begin{array}{l}\text { Pretest willingness to support people with bipolar } \\
\text { disorder }\end{array}$ & .43 & .15 & $.42 * *$ & .40 & .13 & $.38 * *$ \\
\hline Identification with Pat & & & & .54 & .16 & $.43 * *$ \\
\hline$R^{2}$ & & $.22 *$ & & & $.39 * *$ & \\
\hline$F$ for change in $R^{2}$ & & 2.77 & & & 11.15 & \\
\hline
\end{tabular}

* indicates significance at $p<.05 ; * *$ indicates significance at $p<.01$

Identification with Pat Sr. did not predict willingness to support people with $\mathrm{OCD}, \beta=-.02, t=-.09, p=.93$, and the overall model was not significant, $F(8,40)=1.69, p=.13$. Similar to OCD stereotypes, the only significant predictor of willingness to support people with OCD was participants' pretest scores on the same measure, $\beta=.47, t=3.28, p$ $<.01$, partial $r=.46$ (see Table 5). 
Table 5. Regression of Willingness to Support People with OCD on Identification with Pat Sr. (Robert De Niro)

\begin{tabular}{lcccccc}
\hline Variable & \multicolumn{3}{c}{ Model 1 } & \multicolumn{3}{c}{ Model 2 } \\
\hline Familiarity with the movie & $B$ & $S E B$ & $B$ & $B$ & $S E B$ & $\beta$ \\
\# of times watched the movie & .04 & .36 & .03 & .05 & .38 & .04 \\
Contact with person with OCD & .02 & .11 & .04 & .02 & .11 & .04 \\
Close friend with OCD & -.02 & .08 & -.04 & -.02 & .09 & -.04 \\
Personal experience with OCD & .27 & .47 & .09 & .28 & .50 & .09 \\
PSR with Robert De Niro & .07 & .42 & .03 & .07 & .42 & .03 \\
Pretest willingness to support people with OCD & .14 & .25 & .08 & .14 & .26 & .08 \\
Identification with Pat Sr & .42 & .13 & $.47 * *$ & -.42 & .13 & $.47^{* *}$ \\
$R^{2}$ & & & & .02 & .21 & -.01 \\
$F$ for change in $R^{2}$ & & .13 & & & .10 &
\end{tabular}

$* *$ indicates significance at $p<.01$

As for major depression, identification with Tiffany positively predicted willingness to support people with depression, $\beta=.29, t=2.23, p<.05$, partial $r=.32$, and the overall model was significant, $F(8,43)=5.26, p<.001$, adjusted $R^{2}$ $=.40$. The more participants identified with Tiffany, the greater their willingness to support people with major depression (see Table 6). H2 was partially supported.

Table 6. Regression of Willingness to Support People with Depression on Identification with Tiffany (Jennifer Lawrence)

\begin{tabular}{lccccccc}
\hline & \multicolumn{3}{c}{ Model 1 } & \multicolumn{3}{c}{ Model 2 } \\
Variable & $B$ & SE B & $B$ & $B$ & $S E B$ & $\beta$ \\
\hline Familiarity with the movie & & .08 & .28 & .05 & -.08 & .27 & -.05 \\
\# of times watched the movie & .00 & .08 & .01 & -.03 & .08 & -.06 \\
Contact with person with depression & .02 & .08 & .02 & -.00 & .08 & -.01 \\
Close friend with depression & .31 & .37 & .11 & -.26 & .36 & -.09 \\
Personal experience with depression & & .13 & .37 & .05 & .01 & .36 & .00 \\
PSR with Jennifer Lawrence & & .05 & .18 & .04 & -.02 & .17 & -.01 \\
Pretest willingness to support & people with & .75 & .14 & $.66^{* *}$ & .63 & .14 & $.55^{* *}$ \\
depression & & & & & & & \\
Identification with Tiffany & & & & & $.30^{*}$ & .12 & .28 \\
$R^{2}$ & & & $.44^{* *}$ & & & $.50^{* *}$ & \\
$F$ for change in $R^{2}$ & & & $4.87^{* *}$ & & & $4.98^{* *}$ & \\
\hline
\end{tabular}

$*$ indicates significance at $p<.05 ; * *$ indicates significance at $p<.01$

4.1.3 Hypothesis Three

$\mathrm{H} 3$ predicted empathy felt toward a character with mental illness would mediate the relationship between identification and negative stereotypes for the character's condition. Empathy felt toward Pat (indirect effect $=-.15, S E=.08$ ) mediated the relationship between identification with Pat and negative stereotypes about bipolar disorder. The generated bootstrap confidence interval excluded zero (lower limit $=-.271$, upper limit $=-.041$ ). The stronger participants' identification with Pat, the greater the empathy felt toward his character, and the lower the negative stereotypes reported about bipolar disorder, $t=-6.37, p<.001$ (see Figure 1). 


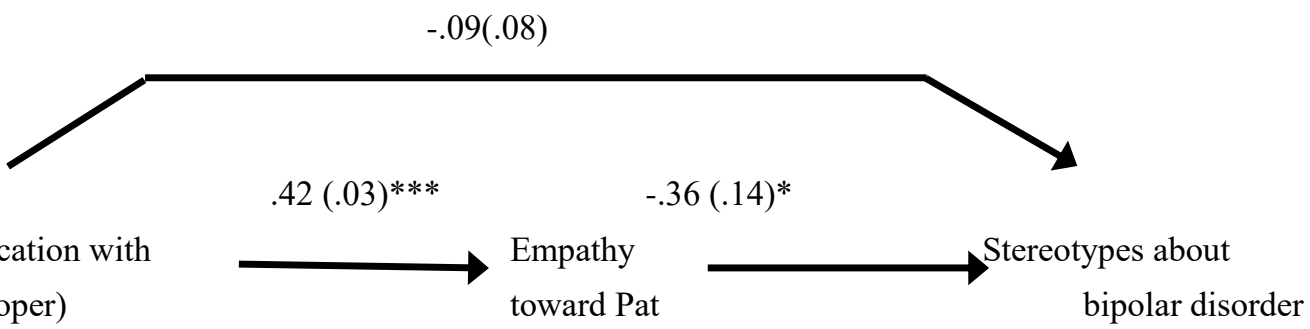

Figure 1. Mediation model of empathy toward Pat on the relationship between identification with Pat and negative stereotypes about bipolar disorder.

Note: Indirect effect of empathy $=-.15(.06), p<.05$, bootstrap confidence interval $(-.271,-.041)$. Standard errors are reported in parentheses. $*(\mathrm{p}<.05) . * * *(p<.001)$.

Empathy toward Pat Sr. (indirect effect $=-.09, S E=.06$ ) did not mediate the relationship between identification and negative stereotypes about OCD. The generated bootstrap confidence interval included zero (lower limit $=-.202$, upper limit $=.029)$. Empathy with Pat Sr. was not a significant predictor of reported negative stereotypes toward people with $\operatorname{OCD}(b=-.21, s e=.12, \mathrm{t}=-1.76, p=.081)$. However, identification with Pat $\mathrm{Sr}$. did positively predict empathy for Pat Sr. $(b=.42, s e=.03, \mathrm{t}=14.32, p<.001)$.

Empathy toward Tiffany (indirect effect $=-.33, S E=.07$ ) mediated the relationship between identification with Tiffany and negative stereotypes about depression. The generated bootstrap confidence interval excluded zero (lower limit $=$ -.478 , upper limit $=-.204$ ). Significant direct relationships were also found between empathy, level of identification, and negative stereotypes about major depression. The stronger the identification with Tiffany, the greater the empathy felt toward her, and in turn, the lower the negative stereotypes reported for major depression, $t=-7.31, p<.001$ (see Figure 2). Overall, H3 was partially supported.

$.06(.07)$
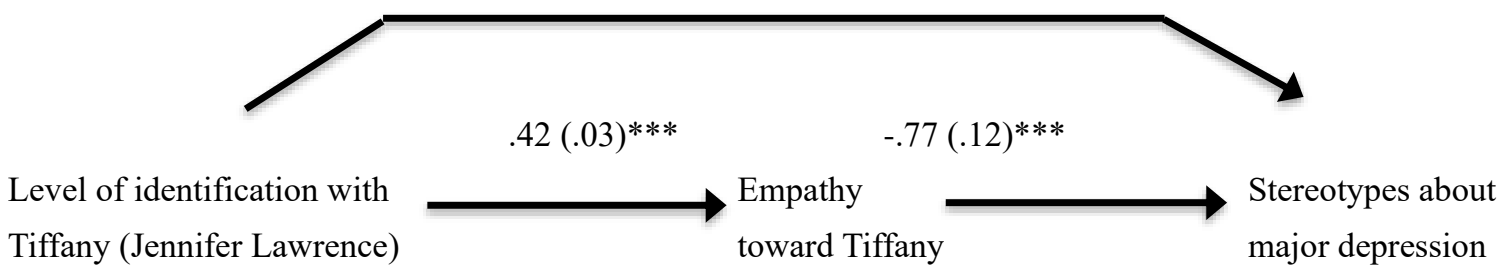

Figure 2. Mediation model of empathy toward Tiffany on the relationship between identification with Tiffany and negative stereotypes about major depression

Note: Indirect effect of empathy $=-.33(.07), p<.05$, bootstrap confidence interval $(-.478,-.204)$. Standard errors are reported in parentheses. ${ }^{* * *}(p<.001)$.

\section{Discussion}

This study extends research on the mediated intergroup contact hypothesis by cutting out the "middle man" (e.g., identification with an in-group character positively interacting with an out-group character) and demonstrating that media users can reduce their stereotyping through identification with out-group characters. Additionally, this study contributes to research on stigmatized health issues and entertainment media by testing the MICH a mental illness context. Most MICH and PCH research has focused on either issues of prejudice and stigma based on race or sexual orientation. To the authors' knowledge, only one study has examined PCH and the role entertainment plays in reducing mental illness stigma (Hoffner \& Cohen, 2012), but it used a cross-sectional survey design precluding it from demonstrating causality. This present study tested MICH in a mental illness context to determine whether exposure to a character with a mental illness leads to reduced stereotypes about that condition and increased intent to help others with the same illness.

$\mathrm{H} 1$ predicted that as identification with a character with mental illness increased, negative stereotypes associated with that illness would decrease. Results indicated that for Pat and Tiffany, identification negatively predicted stereotypes about bipolar disorder and major depression, respectively. However, identification with Pat Sr. did not predict OCD stereotypes. The main predictor was the respondents' pretest stereotypes about OCD. 
$\mathrm{H} 2$ continued the pattern of significant results for Pat and Tiffany and non-significant results for Pat Sr. For the Pat/bipolar and Tiffany/depression conditions, identification positively predicted intent to help others with the associated mental illness, controlling for covariates. Identification has been argued as a pathway through which entertainment media helps to reduce mental illness stigma (Caputo \& Rouner, 2011). The results provide further empirical support for this claim. However, this relationship was not significant for the Pat Sr./OCD condition, which will be discussed later in this section.

H3 was partially supported. In the bipolar and major depression conditions, state empathy partially mediated the relationship between identification and negative stereotypes about the associated mental illness, while controlling for covariates. Additionally, significant direct relationships were found between identification, empathy, and stereotypes about mental illness for both conditions. However, empathy did not mediate the relationship between identification and negative stereotypes in the Pat Sr/OCD condition. Additionally, while there was a significant positive direct relationship between identification and empathy, empathy for Pat Sr. did not negatively predict stereotypes about OCD. Thus, $\mathrm{H} 3$ received partial support.

The results for the bipolar and major depression conditions indicate that empathy serves as the mechanism to explain the relationship between identification and stereotypes toward mental illness. The role of affect, in particular empathy, has been shown to be important for reducing stigma toward out-groups (Oliver et al., 2012). Hence, entertainment media programs aimed at combating stigmatizing attitudes and behaviors of their audiences need to elicit strong feelings of empathy toward the stigmatized characters.

Interestingly, neither identification nor state empathy with the character depicting OCD (Pat Sr.) impacted participants' OCD stereotypes. This lack of significance may be due to three reasons. First, the film did not depict Pat Sr.'s OCD as pronouncedly as Pat's bipolar disorder and Tiffany's major depression. Possibly, viewers in Pat Sr.'s condition missed that he had OCD, especially since most of his OCD rituals were associated with sports superstitions. The study did not include a manipulation check to verify that participants correctly identified the mental illness associated with the characters. Because of this limitation, the researchers do not know if participants in the Pat Sr. condition detected the character's OCD.

A second reason to explain the lack of significance in the OCD condition is that participants reported weaker identification with Pat Sr. compared to Pat and Tiffany. Given that strong identification was important for reducing stereotypes about mental illness, this may explain why there was less OCD stereotype reduction in the posttest. Thirdly, OCD may be a less stigmatized and understood mental illness compared to bipolar disorder or major depression to begin with. Respondents might not have had a clear understanding of OCD. For instance, while OCD affects a little over $2 \%$ of the U.S. adult population (NAMI, 2012), $43.8 \%$ of participants indicated that they or a close family member had OCD. This percentage seems high, indicating that respondents may not have an accurate grasp of the disorder, and perceived it as less of a serious mental illness condition and more of a personality quirk.

Another limitation was the stimuli's ecological validity. Clearly, people do not watch movies as condensed, 13-minute vignettes and usually, there is a focus on more than one character. However, the shortened videos were used for many reasons. First, the condensed videos allowed the researchers to see how the stigma reduction functioned with a focused exposure to a character (as opposed to seeing that character intermittently in a full-length film). This study's success has implications for how impactful short exposures to stigmatized group representatives could be at reducing stereotypes. For example, researchers could test how the stigma reduction functions through viewing short, videos of stigmatized people's struggles (e.g. The "It gets better campaign" for gay youths). A second reason for using the shorter, character-focused videos was to isolate the mental illness for the experimental manipulation as discussed in the method section. The third reason was the ease of data collection. The researchers thought that asking participants to watch a two-hour movie and then take a survey would reduce participation and increase the likelihood of participants not fully watching the entire movie (especially since almost $20 \%$ of participants failed the attention check question for the 13-minute videos).

This study highlights how entertainment media can be used to address stigmatized health issues. To reduce prejudice toward stigmatized out-groups, media out-group portrayals should feature characters that audiences can connect with and relate to. Additionally, the stigmatized issue needs to be portrayed accurately and realistically so that viewers see how the health issue impacts a character's life. The portrayals should depict the characters as well-rounded people living with an illness rather than people defined by their "illness" or stigma (e.g., a person living with breast cancer vs. a breast cancer survivor). Silver Linings Playbook is a good example of a story that presents characters that are living with an illness but are not defined by it. 


\subsection{Future Research}

This study sets the stage for future research to test the mediated intergroup contact hypothesis in other health contexts involving a stigmatized condition (e.g., autism spectrum disorder). Future studies could also move beyond the focus of stigma reduction and explore how identification can impact other areas. For example, researchers could examine whether connecting with a character that battles obesity or weight issues in a realistic setting (rather than on a competition show) impacts self-efficacy perceptions. Additionally, future studies could look at how identification with a character managing a health issue increases understanding toward others with that health issue and provides scripts to connect with others with that issue.

In closing, despite some limitations, this study found support for extending the MICH to consider identification with the out-group character rather than relying on an in-group character "middle man" to facilitate a positive out-group interaction. This consideration moves the $\mathrm{MICH}$ away from the traditional conceptualization of its parent theory (i.e., the contact hypothesis) to recognize that media allows people to more easily interact with and potentially identify with out-group members they are unlikely to socialize with in person.

Additionally, this study's results provide support for the important role entertainment can play in reducing stigma toward people living with stigmatized health conditions. The keys to effective destigmatization seem to lay in the entertainment media's abilities to develop characters that viewers can strongly identify and empathize with over the course of the program or series.

\section{References}

Allport, G. W. (1954). The nature of prejudice. New York: Addison-Wesley.

Amir, Y. (1976). The role of intergroup contact in change of prejudice and race relations. In P. A. Katz (Ed.), Towards the elimination of racism (pp. 245-280). New York: Pergamon.

Auter, P. J., \& Palmgreen, P. (2000). Development and validation of a parasocial interaction measure: The audience-persona interaction scale. Communication Research Reports, 17(1), 79-89.

Batson, C. D., Eklund, J. H., Chermok, V. L., Hoyt, J. L., \& Ortiz, B. G. (2007). An additional antecedent of empathic concern: Valuing the welfare of the person in need. Journal of Personality and Social Psychology, 93, 65-74. https://doi.org/10.1037/0022-3514.93.1.65

Benbow, A. (2006). Mental illness, stigma, and the media. The Journal of Clinical Psychiatry, 68, 31-35. https://doi.org/pmid17288505

Caputo, N. M., \& Rouner, D. (2011). Narrative processing of entertainment media and mental illness stigma. Health Communication, 26(7), 595-604. https://doi.org/10.1080/10410236.2011.560787

Centers for Disease Control and Prevention, Substance Abuse and Mental Health Services Administration, National Association of County Behavioral Health \& Developmental Disability Directors, National Institute of Mental Health, \& The Carter Center Mental Health Program. (2010). Attitudes toward mental illness: Results from the Behavioral Risk Factor Surveillance System. Atlanta (GA): Centers for Disease Control and Prevention. Retrieved from https://www.cdc.gov/hrqol/Mental_Health_Reports/pdf/BRFSS_Full\%20Report.pdf

Cohen, J. (2001). Defining identification: A theoretical look at identification of audiences with media characters. Mass Communication \& Society, 4(3), 245-264. https://doi.org/10.1207/S15327825MCS0403_01

Cohen, J. (2006). Audience identification with media characters. In J. Bryant \& P. Vorderer (Eds.), The psychology of entertainment (pp. 183-197). Mahwah, NJ: Erlbaum.

Cohen, J. (2009). Mediated relationships and media effects: Parasocial interaction and identification. In R. L. Nabi \& M. B. Oliver (Eds.), The SAGE handbook of media processes and effects (pp. 223-236). Thousand Oaks, CA: Sage.

Cortese, J., \& Rubin, A. M. (2010). Uses and Gratifications of Television Home Shopping. Atlantic Journal of Communication, 18(2), 89-109. https://doi.org/10.1080/15456870903554924

Desforges, D., Lord, C., \& Pugh, M. (2007). Role of group representativeness in the generalization part of the contact hypothesis. Basic And Applied Social Psychology, 19(2), 183-204.

Dibble, J. L., Hartmann, T., \& Rosaen, S. F. (2016). Parasocial interaction and parasocial relationship: Conceptual clarification and a critical assessment of measures. Human Communication Research, 42(1), 21-44. https://doi.org/10.1111/hcre.12063

Diefenbach, D. L. (1997). The portrayal of mental illness on prime-time television. Journal of Community Psychology, 25(3), 289-302. https://doi.org/10.1002/(SICI)1520- 6629(199705)25:3<289::AID-JCOP5>3.0.CO;2-R 
Eyal, K., \& Dailey, R. M. (2012). Examining relational maintenance in parasocial relationships. Mass Communication and Society, 15(5), 758-781. https://doi.org/10.1080/15205436.2011.616276

Fennell, D. \& Boyd, M. (2014). Obsessive-compulsive disorder in the media. Deviant Behavior, 35(9), 669-686. https://doi.org/10.1080/01639625.2013.872526

Fujioka, Y. (1999). Television portrayals and African-American stereotypes: Examination of television effects when direct contact is lacking. Journalism \& Mass Communication Quarterly, 76(1), 52-75. https://doi.org/10.1177/107769909907600105

Granello, D. H., \& Pauley, P. S. (2000). Television viewing habits and their relationship to tolerance toward people with mental illness. Journal of Mental Health Counseling, 22(2), 162-175.

Hayes, A. (2016). Process Macro (Version 2.16) [Software]. Available from http://www.processmacro.org/download.html

Hoffner, C. A., \& Cohen, E. L. (2012). Responses to obsessive-compulsive disorder on Monk among series fans: Parasocial relations, presumed media influence, and behavioral outcomes. Journal of Broadcasting \& Electronic Media, 56(4), 650-668. https://doi.org/10.1080/08838151.2012.732136

Horton, D., \& Wohl, R. R. (1956). Mass communication and parasocial interaction. Psychiatry, 19, 215-229.

Joyce, N., \& Harwood, J. (2012). Improving attitudes through televised vicarious intergroup contact. Communication Research, 41(5), 627-643. https://doi.org/10.1177/0093650212447944

Kanazawa, S. (2002). Bowling with our imaginary friends. Evolution and Human Behavior, 23(3), 167-171. https://doi.org/10.1016/S1090-5138(01)00098-8

Klin, A. \& Lemish, D. (2008). Mental disorders stigma in the media: Review of studies on production, content, and influences. Journal of Health Communication: International Perspectives, 13, 434-449. https://doi.org/10.1080/10810730802198813

Ma, Z. (2017). How the media cover mental illnesses: A review. Health Education, 117(1), 90-109. https://doi.org/https://doi.org/10.1108/HE-01-2016-0004

McLaughlin, B., \& Rodriguez, N. S. (2017). Identifying with a stereotype: The divergent effects of exposure to homosexual television characters. Journal of Homosexuality, 64(9), 1196-1213. https://doi.org/10.1080/00918369.2016.1242335

Moyer-Gusé, E. (2008). Toward a theory of entertainment persuasion: Explaining the persuasive effects of entertainment-education messages. Communication Theory, 18(3), 407-425. https://doi.org/10.1111/j.1468-2885.2008.00328.x

Murphy, S. T., Frank, L. B., Chatterjee, J. S., \& Baezconde-Garbanati, L. (2013). Narrative versus nonnarrative: The role of identification, transportation, and emotion in reducing health disparities. Journal of Communication, 63(1), 116-137. https://doi.org/10.1111/jcom.12007

NAMI. (2012). Obsessive-compulsive disorder. from http://www.nami.org/Content/NavigationMenu/Inform_Yourself/About_Mental_Illness/By_Illness/Obsessive-Co mpulsive_Disorder_(OCD).htm

Oliver, M. B., Dillard, J. P., Bae, K., \& Tamul, D. J. (2012). The effect of narrative news format on empathy for stigmatized groups. Journalism \& Mass Communication Quarterly, 89(2), 205-224. https://doi.org/10.1177/1077699012439020

Ortiz, M., \& Harwood, J. (2007). A social cognitive theory approach to the effects of mediated intergroup contact on intergroup attitudes. Journal of Broadcasting \& Electronic Media, 51(4), 615-631.

Page-Gould, E., Mendoza-Denton, R., \& Tropp, L. R. (2008). With a little help from my cross-group friend: Reducing anxiety in intergroup contexts through cross-group friendship. Journal of Personality \& Social Psychology, 95(5), 1080-1094.

Park, S.-Y. (2012). Mediated intergroup contact: Concept explication, synthesis, and application. Mass Communication and Society, 15(1), 136-159. https://doi.org/10.1080/15205436.2011.558804

Parrott, S. \& Parrott, C.T. (2015). Law \& disorder: The portrayal of mental illness in US crime dramas. Journal of Broadcasting \& Electronic Media, 58(4), 640-657. https://doi.org/10.1080/08838151.2015.1093486

Peng, W. Lee, M., \& Heeter, C. (2010). The effects of a serious game on role-taking and willingness to help. Journal of Communication, 60, 723-742. https://doi.org/10.1111/j.1460-2466.2010.01511.x 
Pettigrew, T. F., \& Tropp, L. R. (2006). A meta-analytic test of intergroup contact theory. Journal of Personality and Social Psychology, 90(5), 751-783.

Potter, W. J., \& Zillmann, D. (2009). Conceptualizing the audience. In R. L. Nabi \& M. B. Oliver (Eds.), The Sage Handbook of Media Processes andEeffects (pp. 19-34). Thousand Oaks, CA: Sage Publications.

Rothbart, M., \& John, O. P. (1985). Social categorization and behavioral episodes: A cognitive analysis of the effects of intergroup contact. Journal of Social Issues, 41, 81-104.

Rubin, A. M., \& Perse, E. M. (1987). Audience activity and soap opera involvement: A uses and effects investigation. Human Communication Research, 14(2), 246-268. https://doi.org/10.1111/j.1468-2958.1987.tb00129.x

Russell, D. O. (Writer). (2012). Silver Linings Playbook [Motion picture]. In D. Gigliotti, B. Cohen \& J. Gordon (Producer). United States: The Weinstein Company.

Schiappa, E., Gregg, P. B., \& Hewes, D. E. (2005). The parasocial contact hypothesis. Communication Monographs, 72(1), 92-115. https://doi.org/10.1080/0363775052000342544

Schiappa, E., Gregg, P. B., \& Hewes, D. E. (2006). Can one TV show make a difference? Will \& Grace and the parasocial contact hypothesis. Journal of Homosexuality, 51(4), 15-37. https://doi.org/10.1300/J082v51n04_02

Shen, L. (2010). On a scale of state empathy during message processing. Western Journal of Communication, 74(5), 504-524. https://doi.org/10.1080/10570314.2010.512278

Siegel, D.E. (2014). The portrayal of characters with obsessive-compulsive disorder in American films (Publication No. 3619273). [Doctoral dissertation, University of Hartford] Retrieved from http://search.proquest.com/docview/1534363782

Stout, P. A., Villegas, J., \& Jennings, N. A. (2004). Images of mental illness in the media: Identifying gaps in the research. Schizophrenia Bulletin, 30, 543-561.

Stuart, H. (2016). Reducing the stigma of mental illness. Global Mental Health, 3(17). https://doi.org/10.1017/gmh.2016.11

Tal-Or, N., \& Cohen, J. (2010). Understanding audience involvement: Conceptualizing and manipulating identification and transportation. Poetics, 38(4), 402-418. https://doi.org/10.1016/j.poetic.2010.05.004

Tan, A., Fujioka, Y., \& Lucht, N. (1997). Native American stereotypes, TV portrayals, and personal contact. Journalism \& Mass Communication Quarterly, 74, 265-284.

van $\mathrm{t}^{`}$ Veer, J. T. B., Kraan, H. F., Drosseart, S. H. C., \& Modde, J. M. (2006). Determinants that shape public attitudes toward the mentally ill. Social Psychiatry and Psychiatric Epidemiology, 41, 310-317.

Wahl, O. F., (1992). Mass media images of mental illness: A review of the literature. Journal of Community Psychology, 20(4), 343-352.

Whal, O. F., Hanrahan, E., Karl, K., Lasher, E., \& Swaye, J. (2007). The depiction of mental illnesses in children's television programs. Journal of Community Psychology, 35(1), 121-133. https://doi.org/10.1002/jcop.20138

World Health Organization (2017). Public health round-up. Bulletin of the World Health Organization, 95, 244-245. https://doi.org/10.2471/BLT.17.010417

World Health Organization. (28, November 2019). Mental disorders. Retrieved from http://www.who.int/en/news-room/fact-sheets/detail/mental-disorders

Wright, S. C., Aron, A., McLaughlin-Volpe, T., \& Ropp, S. A. (1997). The extended contact effect: Knowledge of cross-group friendships and prejudice. Journal of Personality and Social Psychology, 73(1), 73-90. https://doi.org/10.1037/0022-3514.73.1.73

Yakelovich, D.Y. (1990). Public attitudes toward people with chronic mental illness. Unpublished manuscript prepared for the Robert Wood Johnson Foundation Program on Chronic Mental Illness.

\section{Copyrights}

Copyright for this article is retained by the author(s), with first publication rights granted to the journal.

This is an open-access article distributed under the terms and conditions of the Creative Commons Attribution license which permits unrestricted use, distribution, and reproduction in any medium, provided the original work is properly cited. 